\title{
Job Motivation and Associated Factors Among Health Care Professionals Working in Public Health Facilities of Gedeo Zone, Southern Ethiopia
}

\author{
Nafkot Berhanu ${ }^{1}$, Berhane Megerssa Ereso², Gebeyehu Tsega Nebeb ${ }^{2, *}$ \\ ${ }^{1}$ Southern Nations and Nationalities Region (SNNR) Health Bureau, Hawasa, Ethiopia \\ ${ }^{2}$ Department of Health Economics, Management and Policy, Institute of Health, Jimma University, Jimma, Ethiopia \\ Email address: \\ nafkihealth@gmail.com (N. Berhanu), berhanemegerssa2004@gmail.com (B. M. Ereso), gebishts@gmail.com (G. T. Nebeb) \\ *Corresponding author
}

\section{To cite this article:}

Nafkot Berhanu, Berhane Megerssa Ereso, Gebeyehu Tsega Nebeb. Job Motivation and Associated Factors Among Health Care Professionals Working in Public Health Facilities of Gedeo Zone, Southern Ethiopia. Clinical Medicine Research.

Vol. 6, No. 1, 2017, pp. 9-22. doi: 10.11648/j.cmr.20170601.12

Received: January 19, 2017; Accepted: January 31, 2017; Published: February 27, 2017

\begin{abstract}
Since the level of job motivation and associated factors among health care professionals in public health institutions in Gedeo Zone is not yet studied the objective of this study is to assess Level of job motivation and associated factors among health care professionals in public health institutions of the Zone. A cross-sectional study design was conducted in 36 health center of Gedeo zone, during February 20 to May 10, 2015. The data were analyzed using SPSS. Factor score was computed for the items identified to represent the level of job motivation. Using this regression factor score, multivariate linear regression analysis was performed. More than three quarter $77.4 \%$ (226) of the respondents were discourage from working hard for different reasons. only 57 (19.5\%) of Health care professionals working in public health centers were highly motivated, only $6.2 \%$ (18) of them are rewarded for their hard working. Sex, communication, resource availability, inadequate salary, feedback, training, working environment, workload and recognition were negative determinates of job motivation. The motivation of Health professional in Gedo zone is low. Since half of the professionals were demotivated, healthcare organizations should maximize its effort to practice incentive schemes.
\end{abstract}

Keywords: Job Motivation, Health Care, Gedo Zone, Health Care Professionals

\section{Introduction}

Motivation is an internal psychological process. It is not possible to "motivate" people directly, only to create an environment conducive to high degrees of motivation. Further, motivation itself is not an observable phenomenon; it is only possible to observe either the results of the motivational process (such as improved performance) or perhaps, some of the determinants of motivation [1].

Increased motivation creates the conditions for a more effective workforce, but because work motivation is an interactive process between workers and their work environment, good management and supervision are still critical factors in reaching organizational goals. Motivation is crucial for organizations to function; without motivation employees will not put up their best and the organization's performance would be less efficient. Human resource management (HRM) systems in developing countries are weak and fragmented in the majority of health care organizations [1, 2, 3].

During the last decade a growing emphasis has been placed on the importance of motivated health workers in providing good quality health care. The 2006 World Health Report discussed at length the challenge of making the most of the existing health workers and it was stated that "developing capable, motivated and supported health workers is essential for overcoming bottlenecks to achieve national and global health goals" [4].

In 2008, the Kampala Declaration of the Global Health Workforce Alliance further emphasized the importance of motivated health workers in service delivery. WHO similarly has pointed out that "the ability of a country to meet its health goals depends largely on the knowledge, skills, 
motivation and deployment of the people responsible for organizing and delivering health services"[5].

The increased focus on health workers' motivation as vital to ensure good quality health services is a very important shift from seeing quality of service delivery in the health sector as a function of the number of health workers and their qualifications. This shift warrants a further discussion of motivation of health workers in low-income settings. A systematic review study of motivation in low-income countries concluded that "high quality care cannot be provided unless issues of de- motivated staff are comprehensively addressed" [6].

Health professionals are at the heart of any health system and a well-motivated workforce is a prerequisite for a functioning health system. The WHO report states that the issues around staff shortages, brain drain, low motivation and poor performance of human resource in Sub-Saharan Africa are so enormous that some termed it as 'Africa health workforce crises'. In order to achieve the MDGs the region would require a $139 \%$ increase in health workers [7-12].

The African continent is currently facing serious human resource crisis in the health sector $(9,12)$. These severe human resource shortages have affected the ability of many countries to initiate and sustain credible health services. Although several reforms and policies have been developed to address health problems in the continent little attention has been given to required human resources and their motivation [9, 13 and 14].

The severely limited number of health professionals in sub-Saharan Africa negatively affects all types of health outcomes and threatens to limit the attainability of the Millennium Development Goals. The World Health Report is dedicated to recognizing and addressing these workforce shortages. The report identified a total of 57 countries that had a critical shortage of healthcare employees with a global deficit of 2.4 million doctors, nurses, and midwives [4].

Ethiopia has one of the greatest shortages with a density of only 0.03 physicians, 0.23 clinical nurses, and 0.02 midwives per 1,000 people in 2010. Several areas of human resources have been linked with barriers to achieving the Millennium Development Goals including low morale and motivation of health care workers, poor policies and practices for human resource development, and lack of supportive supervision for health workers $[10,11]$.

The Ethiopian Federal Ministry of Health has recently emphasized the need to produce and retain more health workers, and increased efforts to improve human resource management in public health institutions. Experts in human resource management recognize the significant relationship between poor staff motivation, particularly in low-income countries [15-16].

In Ethiopia, the mission of the public sector is to provide adequate health services to all segments of the population, has been eroded by decades of central planning, weak monetary incentives and poor accountability, leading to widespread opportunism on the part of public healthcare providers [17].

Identified de-motivating factors as, lack of incentives, poor inter-professional relations, poor communication system, poor salaries, lack of promotions, unmet expectations, poor access to training opportunities, working conditions and inadequate facilities for performing expected duties, lack of concern by employers for staff welfare, lack of participation in decision-making, poor information flow to and from health management [18-19].

Lack of human resource management capacity in the public sector health institutions is one of the profound problems in Ethiopia. At the same time managing human resource management functions of health service institutions seems to be a neglected part, i.e. in most government health institutions of Ethiopia most of the human resource related activities are left for those who are not trained in managing human resource and also having other clinical responsibilities. This, in turn, results into mismanagement of the very scarce human resource in the health sector [3].

Overall, there is supportive policy environment (health policy and strategy, capacity building policy and strategy, civil service reform etc.) and a growing recognition at policy level that "Health is not only a byproduct of social changes but an instrument to promote such changes and health workers are in the vanguard". However, most policy and strategy documents are dated (early 1990s) and there are no specific and newly updated policy and strategy documents on HRM [20].

Available data indicate that "health sector salaries seem more or less in line with the minimum cost-of-living increases and are favorable relative to other factors. "Base salaries of health personnel increased by at least $21 \%$ from $1999-2003$ in nominal terms (40\% in real terms)' HR management is a dynamic process and there will be need to adjust to changing situations [21].

Motivation is one of the most important factors in affecting human behavior and performance. The level of motivation an individual or team exerted in their work task can affect all aspects of organizational performance. As mentioned by Project Management Institute (2008), the overall success of the organizational project depends on the project team's commitment which is directly related to their level of motivation. As employees are the main resources for organizations' business activities, the issues of employees' motivation will critically decide organizations' success. As a result, refer to Bourgault et al. (2008), organizations should obtain a clear understanding in employees' dissimilarities in needs and preferences for motivation factors to boost up their performance towards overall organization goal [22].

"Low motivation has a negative impact on the performance of individual health workers, facilities and the health system as a whole. Moreover, it adds to the push factors for migration of health workers, both from rural areas to the cities and out of the country. It is therefore an important goal of human resources management in the health sector to strengthen the motivation of health workers..." [23].

So, this indicates that there is a gap in practicing motivational measures to employee complaining with the motivational theory in our country. In the study area what is practically seen is around $20 \%$ health centers there is drug supply shortage, water, electricity, housing, roads are 
problems, there are also health care professionals who don't respect the working hours, in some health centers human resource management activities is done by health care professionals who have no clear ideas about HRM procedures, some health professionals simply sit while clients are in need of their helps, regarding the goal achievements there is gap per each health centers. If the strategy of motivation were followed in all institutions, there would be a chance to have motivated employee who is committed to achieve organizational goals. There for, the objective of this study is to asses the level of motivation and associated factors in Gedo Zone, southern Ethiopia.

\section{Methods and Materials}

The facility based cross-sectional study was conducted from February 25/2015 to March 5/2015 in Gedeo zone, which is located in SNNPR at $360 \mathrm{~km}$ far from Addis Ababa in south direction and $89 \mathrm{~km}$ far from the regional city Hawassa in south East. The area of the zone is 25,640 Hectare and 1500-2380 feet above sea level. Total population in the zone is 1.1 million. It has woyenadega climatic condition and the average temperature of the zone is $22^{\circ} \mathrm{C}$. It has annual rainfall of $1895 \mathrm{~mm}^{3}$. The zone has 8 Woredas $(6$ Woreda administration and 2 town administration), there are 36 health centers with 661 health professionals.

Randomly selected Senior Health care professionals working in public Health centers of Gedeo zone at the time of data collection, Health centers heads and Human resource management facilitators/coordinators were the study population of the study. All categories of diploma nurses, BSC nurses, midwife nurses, midwife BSC, Health officers, Environmental health officers and laboratory technologist, pharmacist, druggist and laboratory technicians were the study participants of the study.

The sample size of the study was determined by single population proportion formula

Assuming, 5\% marginal error and confidence interval of $95 \%$. Fifty percent proportion has been preferred due to lack of similar studies in Ethiopia and to get maximum sample size, accordingly the sample size calculated to be 384 . The final sample size calculated by using finite population correction formula since study population $(\mathrm{N}=661)$ is less than 10,000 .

Adding non-response rate of $20 \%$, total sample size of 243 $+49=292$ health professionals were selected.

For In-depth interview (IDI) 10 senior health care professionals (those health care professionals work in the public health facility for 6 years and above), 8 heads of Health centers \& 9 human resource management facilitators/coordinators were included.

A computer based simple random sample was used to select 292 participants from the source population. Job motivation was the outcome variable of the study while Socio demographic factors (age, sex, educational background, work experience, religion, ethnicity, marital status \& educational status), communication (relationship between management and staff), availability of basic medical supplies, salary, workload, training distribution and opportunity for education were the independent variables of our study.

Self-administered questionnaire was given to Health care professionals to fill their responses by data collectors while giving the questionnaire for the selected health care professionals they were told about the objectives of the study $\&$ appoint them when to return the questionnaire.

The tools and the concepts utilized for this study have been used in high-income countries and they were recently applied in African settings to measure health worker motivation. The tools were directly adapt from study done in Zambia to measure job motivation of health worker in public health facilities because of there is no available tools that has been used in Ethiopia previously [43].

Pre-tested and structured questionnaire was adapted from similar study done in Zambia. The questionnaire was prepared in English; translated in to Amharic and administered in English and Amharic because of at least all of the health care professionals knows English and Amharic. The questionnaire was designed to obtain information on; socio demographic characteristics of respondents, factor affecting motivation \& assessing level of motivation. The questionnaire consisted of five points Lickert scale items, with 1 and 5 indicating the lowest and highest levels agreement, respectively. The response categories for Likert scale items should have five categories to maximize variation. Each of the responses was scored: strongly disagree $=1$, disagree $=2$, undecided $/$ not sure $=3, \quad$ agree $=4$, strongly disagree $=5$. After reversed for negatively worded items to positively worded items, score was summed for each respective factor.

The 23 items that contain 7 constructs with Likert scale (1 strongly agree to 5 strongly disagree), after reversing negative worded items 292 data were subjected to principal component analysis (PCA) using SPSS Version 20. At the point assumption come across 14 items remained in 3 component with Kaiser Meyer-Oklin (KMO) value 0.888, Bartlett's Test of Sphericity was less than 0.001, Communality for all items were above $0.5,3$ components with eigenvalues exceeding 1, explain $64.193 \%$ of the variance with internal reliability (Cronbachs' alpha) estimates of 0.601 the data were used for further analysis.

The self-administered questionnaire is distributed and collected by 16 trained diploma graduate nurse who were excluded from the study due to their service year and unselected for self-administered questionnaire. The nurses were trained for one day by the principal investigator on the study instrument, study objective, consent form, how to distribute the questionnaire and collect it. The individual depth interview was conducted by principal investigator; one Health officer was recruited and participated by note taking.

Before the actual data collection, the quantitative questionnaire was pre-tested on 5\% (14) of the total sample size outside the study area in Sedama zone 'Qebado' Health center. The purpose of the pre-testing is check clarity of the instructions, any questions were unclear or ambiguous, 
whether there were any major topic omissions, ensure that the respondents were able to understand the questions, to check the wording, logic and any other comment. Two (2) questions were clarified after pre-testing.

After data collection, each questionnaire was checked for completeness and code was given before data entry. Data was entered, cleaned, explored for outliers, missed values, missed variables and edited by using EPIDATA V.3.2. Different frequency tables, graphs and descriptive summaries were used to describe the study variables. Correlation between dependent and independent variables was checked by using binary and multivariate linear regression. On binary linear regression a $\mathrm{p}$-value $\leq 0.25$ was used as a candidate for multivariate linear regression analysis. Statistical significant correlation was tested at a $\mathrm{p}$-value of $<0.05$. Finally only those independent variables that maintain their association with outcome variables in multiple linear regressions were used to construct the final models. To level job motivation principal component analysis was used. Variables with correlations greater than 0.30 and Kaiser-Meyer-Olkin (KMO) measure of sampling adequacy greater than 0.5 support variables retention in analysis. Each variables with communality $<0.5$ was removed from analysis and Variables with complex structure having high loadings or correlations $>=0.40$ on more than one component were removed from analysis. Then appropriate number of factors was determined. The components explain at least $50 \%$ of the variance in each of the variables was included in the final analysis. The communalities for all of the variables was included on the components were greater than 0.50 and all variables have simple structure. After identifying the components the mean of factor analysis component (FAC) for further analysis, items in the final component taken to calculate percentage scale score of job motivation for each individual, then after level of job motivation into quantized it to low motivation, medium motivation and high motivation.

To assure the data quality, data collection tool were adapted from similar study for quantitative study, for qualitative part from different studies and modified according to the local context and objectives of this study by the principal investigator. Initially the questionnaire was prepared in English language then translated to Amharic; national language of Ethiopia. Back translated to English to ensure semantic equivalence. Training was given to data collectors and supervisors by the investigator. Pre-testing of the questionnaire was carried on health care professionals that could not be included in the study, based on the result necessary modification was followed.

At the end of each day, the questionnaire was checked for completeness, accuracy and consistency by the supervisor and data collectors and again rechecked by principal investigator before entered in to EpiData corrective discussion was under taken with all the data collectors and supervisors. Finally Data were cleaned and edited by using EPIDATA V.3.2.

Ethical clearance was obtained from ethical committee of Jimma University, College of Public Health and Medical Science. Permission letter was obtained from SNNPR Regional Health bureau and Gedeo zone Health Department after discussion of the purpose of the study. Similarly after clear discussion about the actual study written informed consent was obtained from each study participates while the study participants right to refuse was also be respected. Different measures were taken to assure the confidentiality of study participant's such as writing their names or any identification in the questionnaire was not be required.

The final result of this study will be presented to Jimma University, College of Health science, disseminated to Regional health bureau, zonal health department and Health centers involved in the study and also communicated to Ministry of health. Further attempt will be made to publish it on national scientific journals.

\section{Results}

A total of 292 self-administered questionnaires were distributed to health professionals working in public health centers found in Gedeo zone. All questionnaires were returned, giving a response rate of $100 \%$. All were complete and has no inconsistencies so that 292 data were found to be useful for analysis.

From study participants $56.2 \%$ (164) of the respondents were male, the average age of the respondents was 28.69 (SD 6.25 ), ranging from 20 years to 50 years. Slightly above half participants were Gedeo in ethnicity followed by Amhara, 44.2 (129) of them were orthodox religion followers, around half were unmarried, all type of health care professionals accounts $74 \%$ (217) which includes clinical nurse, midwifery nurse, public health nurse, Health informatics and sanitarian nurse. The average salary for health care professionals working in public health centers of Gedeo zone is 2,580 (SD 1127) ETB, ranging from 1663 to 7424 per month (Table 1)

Table 1. Socio demographic characteristics of Health Care Professionals working in Public Health Facilities of Gedeo zone, southern Ethiopia, 2015.

\begin{tabular}{|c|c|c|c|c|}
\hline No & Socio Demographic characteristics & & Frequency & Percent \\
\hline \multirow{2}{*}{1} & \multirow{2}{*}{ 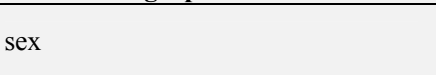 } & Male & 164 & 56.2 \\
\hline & & Female & 128 & 43.8 \\
\hline \multirow{2}{*}{2} & \multirow{2}{*}{ age } & Below 30 yrs. & 218 & 74.7 \\
\hline & & Above 30 yrs. & 74 & 25.3 \\
\hline \multirow{6}{*}{3} & \multirow{6}{*}{ Ethnicity } & Gedeo & 153 & 52.3 \\
\hline & & Oromo & 36 & 12.3 \\
\hline & & Amhara & 41 & 14 \\
\hline & & Gurage & 33 & 11.3 \\
\hline & & Tigre & 20 & 6.8 \\
\hline & & ${ }^{*}$ Others & 9 & 3.1 \\
\hline
\end{tabular}




\begin{tabular}{|c|c|c|c|c|}
\hline No & Socio Demographic characteristics & & Frequency & Percent \\
\hline \multirow{5}{*}{4} & \multirow{5}{*}{ Religion } & Orthodox & 129 & 44.2 \\
\hline & & Protestant & 119 & 40.8 \\
\hline & & Muslim & 26 & 8.9 \\
\hline & & Catholic & 10 & 3.4 \\
\hline & & Others & 8 & 2.7 \\
\hline \multirow{4}{*}{5} & \multirow{4}{*}{ Marital status } & Single & 151 & 51.7 \\
\hline & & Married & 136 & 46.6 \\
\hline & & Divorced & 3 & 1 \\
\hline & & Widowed & 2 & 0.7 \\
\hline \multirow{3}{*}{6} & \multirow{3}{*}{ Experience in health sector } & Below 5 years & 196 & 67.1 \\
\hline & & Between 6 and $10 \mathrm{yrs}$. & 72 & 24.7 \\
\hline & & Above 10 yrs. & 24 & 8.2 \\
\hline \multirow{2}{*}{7} & \multirow{2}{*}{ Educational status } & Diploma & 240 & 82.2 \\
\hline & & Degree & 52 & 17.8 \\
\hline \multirow{8}{*}{8} & \multirow{8}{*}{ Professional background } & All type of nurses & 217 & 74.3 \\
\hline & & BSc Nurses & 14 & 4.8 \\
\hline & & HO & 28 & 9.6 \\
\hline & & Lab Technicians & 11 & 3.8 \\
\hline & & Lab Technology & 4 & 1.4 \\
\hline & & Pharmacy Technicians & 12 & 4.1 \\
\hline & & Pharmacy Technology & 3 & 1 \\
\hline & & Enva HO & 3 & 1 \\
\hline \multirow{3}{*}{9} & \multirow{3}{*}{ Salary } & 1663 ETB (83.15 USD) & 66 & 22.6 \\
\hline & & $1664-3000$ ETB & 152 & 52.1 \\
\hline & & Above $3001 \mathrm{ETB}$ & 74 & 25.3 \\
\hline
\end{tabular}

* Others, Konso, Sidama, Wolyita

There are different factors which could influence motivation of health care professionals working in public health centers in Gedeo zone. Of the respondents $90.4 \%$ (264) were know their job duties, requirements, and the goals are clear and specific, while $9.6 \%$ (28) of the respondents were not (Table 2).

Of the respondents, only $15.8 \%$ (46) believes that their job provides with opportunities for advancement to higher levels jobs, while $84.2 \%$ (246) disagreed. Of the respondents, $52 \%$ (152) complain that they don't get any feedback from their managers or supervisors regarding their job within the last 3 months, while 48\% (140) get feedback (Table 2).

A 36 years old male Health Care Professional from one HC said:

“...in my experience I never seen while my supervisors or managers gave me feedback regarding my work, even they don't supervise the work done"

Among the respondents concerning communication relationships $50.3 \%$ (147) were very satisfied, $27.4 \%$ (80) satisfied, $11.3 \%$ (33) not satisfied and $11 \%$ (32) comments it needs improvement (Table 2).

One of human resource expertise, sex male, age 32, from Yirga cheffe town HC said,

"... Staff communication is smooth, sometimes we heard conflict and then immediately the discipline committee call those who disagreed and arbitrate the conflict among or between them"

Around One fourth of the respondents, happy by the tasks they performed $26 \%$ (76), while $74 \%$ (216) complain there were workload (Table 2).

A 28 years old Female Health Care Professional from one HC said:

"... We received more than 30 lab requests from all department of the health center which is above the average per day than recommended by WHO, sometimes we might report false positive results"

Most respondents $94.9 \%$ (277) are not satisfied with present remuneration or salary/compensation, while only $5.1 \%$ (15) of them are satisfied. Slightly above half of the respondents $52.1 \%$ (152) feel that there are shortage of medical supplies needed for their work (Table 2).

A 30 years old male Health Care Professional from one HC said:

“... I am diploma graduate I worked in this health center for the past 10 years even my salary increased by two fold that it were in the last five year, now a day things are changed, my salary can't goes me through a month (finished before a month)..."

The issues of feedback, communication, workload, salary/compensation and medical supplies influence or affects job motivation of health care professionals working in public health centers of Gedeo zone (Table 2).

Above half $60 \%$ (174) complain that training is not given equally for them, $64.4 \%$ (188) of them also complain that there is no clear path to continue further education, half of the respondents not enjoy their work environment (Table 2).

A 25 years old male Health Care Professional from one HC said:

"... What irritate me is that the issue of training and continuing education, those who has social tie with heads of health sector, and those who are best friends of them used the chance most..."

A 29 years old male Health Care Professional from one HC said:

"...Most of the time opportunity for education is given for BSC graduates this thing upset diploma graduates, they start learning by themselves in private collages education..." 
A 27 years old male Health Care Professional from one HC said

"There is a problem with staff motivation. You work for five or more years in the same place. You find the same person goes to the same training in two years; why not rotate and train someone else the next year?"
As many as 94\% (274) were not rewarded for their hard working but only $6 \%$ (18) got reward for their hard working from their employee. Among those who got reward $0.7 \%$ (2) are promoted, $0.3 \%$ (1) got salary increment and 5.9\% (17) given merit/bonus (Table 2).

Table 2. Showing Different characteristics that exist in public health centers of Gedeo zone, southern Ethiopia, 2015.

\begin{tabular}{|c|c|c|c|}
\hline Variables & Options & Count & Percent \\
\hline \multirow{2}{*}{ Guideline administration } & Yes & 264 & 90.4 \\
\hline & No & 28 & 9.6 \\
\hline \multirow{2}{*}{ Opportunities for advancement levels of job } & Yes & 46 & 16 \\
\hline & No & 246 & 84 \\
\hline \multirow{2}{*}{ Feedback } & Yes & 140 & 47.9 \\
\hline & No & 152 & 52.1 \\
\hline \multirow{4}{*}{ Communication } & Very satisfied & 147 & 50.3 \\
\hline & satisfied & 80 & 27.4 \\
\hline & Not satisfied & 33 & 11.3 \\
\hline & Need improvement & 32 & 11 \\
\hline \multirow{2}{*}{ Workload } & Happy & 76 & 26 \\
\hline & Overworked & 216 & 74 \\
\hline \multirow{2}{*}{ Remuneration or salary/compensation } & Yes & 46 & 15.8 \\
\hline & No & 246 & 84.2 \\
\hline \multirow{2}{*}{ Resource availability } & Yes & 140 & 47.9 \\
\hline & No & 152 & 52.1 \\
\hline \multirow{3}{*}{ Training } & Yes & 118 & 40.4 \\
\hline & No & 174 & 59.6 \\
\hline & Yes & 48 & 16.4 \\
\hline \multirow[t]{2}{*}{ Career development/continuing education } & No & 188 & 64.4 \\
\hline & don't know & 56 & 19.2 \\
\hline \multirow{2}{*}{ Working environmental } & Yes & 146 & 50 \\
\hline & no & 146 & 50 \\
\hline \multirow{4}{*}{ Efforts } & Strongly agree & 38 & 13 \\
\hline & Agree & 99 & 34 \\
\hline & Not sure & 82 & 28 \\
\hline & Disagree & 73 & 25 \\
\hline \multirow{2}{*}{ Reward } & Yes & 18 & 6.2 \\
\hline & No & 274 & 93.8 \\
\hline \multirow{2}{*}{ Promotion } & Yes & 2 & 0.7 \\
\hline & No & 16 & 5.5 \\
\hline \multirow{2}{*}{ Salary increment } & Yes & 1 & 0.3 \\
\hline & No & 17 & 5.9 \\
\hline \multirow{2}{*}{ Bonus/Merit } & Yes & 17 & 5.9 \\
\hline & No & 1 & 0.3 \\
\hline \multirow{2}{*}{ Assistance } & Yes & 226 & 77.4 \\
\hline & No & 66 & 22.6 \\
\hline
\end{tabular}

Out of 292 respondents, $74.4 \%$ (226) are discouraged from working hard for their health center due to reasons presented in fig. 1 below.

Reason what Discourage Health care Professionals not to work hard

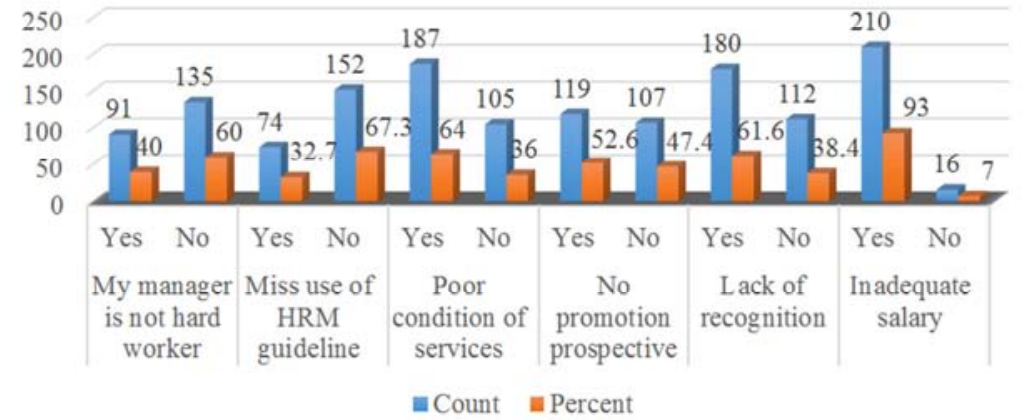

Figure 1. Showing reasons discouraging Health Care Professionals not to work hard in public health centers of Gedeo zone. 
From the respondents above half of them 160 (54.8\%) consider themselves as motivated to work hard, $132(45.2 \%)$ are not motivated to work hard for the health center they are working for (Figure 2).

\section{FEELING OF BEING MOTIVATED}

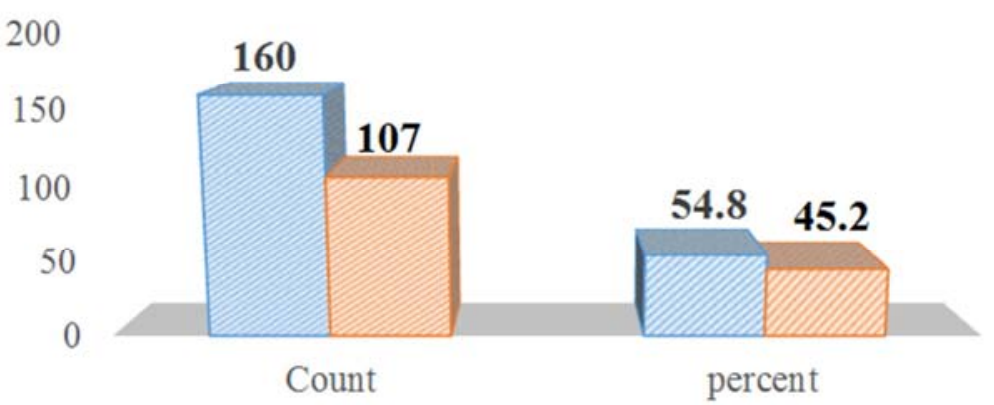

Figure 2. Showing response of health care professionals working in public health center of Gedeo zone about their feeling of motivation to work hard.

Job motivation

After PCA was done the reduced items 14 out of 23 items used to assess the level of motivation and for further data analysis, all the 14 questions taken together as a single index of motivation after calculating the mean of 3 components formed out of 7 constructs (initially) (Table 3).

Table 3. Motivational outcome constructs and questions of health Care professionals working in public health centers of Gedeo zone, southern Ethiopia, 2015.

\begin{tabular}{lllll}
\hline & Descriptive Statistics & & \\
\hline Constructs & Remained Items after data reduction & Mean & Std. Deviation & Analysis N \\
\hline & Only I do this job to get paid & $3.93^{*}$ & 1.030 & 292 \\
& I am often absent form work & 3.20 & 1.123 & 292 \\
& I feel emotionally drained at the end of every day & $3.40^{*}$ & 1.137 & 292 \\
& Sometimes when I get up in the morning, I fear having to face another day a & $3.55^{*}$ & 1.161 & 292 \\
& It is not a problem if I sometimes come late for work & $3.46^{*}$ & 1.176 & 292 \\
General motivation & I am not satisfied with my colleagues in my work & 3.28 & 1.333 & 292 \\
& I do this job as it provides long-term security for me & $3.58^{*}$ & 1.328 & 292 \\
& I feel very little commitment to this health center & 2.89 & 1.331 & 292 \\
& I do not think that my work in this health facility is valuable these days & 2.84 & 1.233 & 292 \\
& I always complete my tasks efficiently and correctly & 3.37 & 1.313 & 292 \\
& Do things that need doing without being asked or told & 1.79 & .896 & 292 \\
& I am punctual about coming to work & 1.89 & .903 & 292 \\
Carefulness & I am proud to be working for this health center & $4.46^{*}$ & .747 & 292 \\
& I am glad that I work for this center rather than other facilities in the country & $4.20^{*}$ & .917 \\
\hline
\end{tabular}

Sign $(*)$ indicate the scale for negatively worded questions was 1 (strongly disagree) to 5 (strongly agree). Thus a high score shows disagreement with a negative statement (Table 3).

Under general motivation constructs 8 items were loaded, 12(4.1\%) strongly agreed, 25 (8.6\%) agreed, 18(6.2\%) neutral, 153(52.4\%) disagree and $84(28.8 \%)$ were strongly disagreed towards they only serve to be paid (Table 4).

Among the respondents respectively 23 (7.9\%) strongly agree, 43 (14.7\%) agree, 57 (19.5\%) neutral, 116 (39.7\%) disagree and $53(18.2 \%)$ strongly disagree that they are not satisfied by their colleague, around one fourth of the health care professional's fears when they get up in morning to face another day of work (Table 4).

A 32 years old Female Health Care Professional from one HC said:

“... Some of my colleagues not give services expected from them, for simple thing they might appoint the clients or refuse to give services, for e.g. while family planning consumables is in store let them for other days, some health care professionals take chair outside (for unfruitful talk) while clients knocking their door for services..."

Concerning carefulness construct $82.5 \%$ of the respondents agreed that they complete their task correctly and efficiently, around $8 \%$ they wait told to do so from their boss (Table 4).

Almost half of the respondents not like the current health center they are working in, $44.2 \%$ of the respondents proud to work for the health center currently working in (Table 4).

A 35 years old male Health Care Professional from one HC said:

“... No one recognize your work, even you perform valuable activities". 
Table 4. Description of variables that measures level of job motivation among health care professionals working in public health facilities of Gedeo zone, southern Ethiopia, 2015.

\begin{tabular}{|c|c|c|c|c|c|c|}
\hline Constructs & Items & Strongly agree & Agree & Not sure & Disagree & $\begin{array}{l}\text { Strongly } \\
\text { disagree }\end{array}$ \\
\hline \multirow{9}{*}{$\begin{array}{l}\text { General } \\
\text { commitment }\end{array}$} & Only I do this job to get paid & $12(4.1 \%)$ & $25(8.6 \%)$ & $18(6.2 \%)$ & $153(52.4 \%)$ & $84(28.8 \%)$ \\
\hline & I do this job as it provides long-term security for me & $27(9.2 \%)$ & $52(17.8 \%)$ & $75(25.7 \%)$ & $111(38 \%)$ & $27(9.2 \%)$ \\
\hline & I feel emotionally drained at the end of every day & $20(6.8 \%)$ & $54(18.5 \%)$ & $46(15.8 \%)$ & $133(45.5 \%)$ & $39(13.4 \%)$ \\
\hline & $\begin{array}{l}\text { Sometimes when I get up in the morning, I fear } \\
\text { having to face another day a }\end{array}$ & $18(6.2 \%)$ & $51(17.5 \%)$ & $31(10.6 \%)$ & $137(46.9 \%)$ & $55(18.8 \%)$ \\
\hline & I am not satisfied with my colleagues in my work & $23(7.9 \%)$ & $43(14.7 \%)$ & $57(19.5 \%)$ & $116(39.7 \%)$ & $53(18.2 \%)$ \\
\hline & I feel very little commitment to this health center & $31(10.68 \%$ & $41(14 \%)$ & $25(8.6 \%)$ & $124(42.5 \%)$ & $71(24.3 \%)$ \\
\hline & $\begin{array}{l}\text { It is not a problem if I sometimes come late for } \\
\text { work }\end{array}$ & $3(1 \%)$ & $22(7.5)$ & $15(5.1)$ & $126(43.2 \%$ & $126(43.2 \%$ \\
\hline & $\begin{array}{l}\text { I do not think that my work in this health facility is } \\
\text { valuable these days }\end{array}$ & $34(11.6 \%)$ & $37(12.7 \%)$ & $28(9.6 \%)$ & $111(38 \%)$ & $82(28.1 \%)$ \\
\hline & I am often absent from work & $4(1.4 \%)$ & $6(2.1 \%)$ & $3(1 \%)$ & $117(40.1 \%)$ & $162(55.5 \%)$ \\
\hline \multirow{3}{*}{ Carefulness } & I always complete my tasks efficiently and correctly & $130(44.5 \%)$ & $111(38 \%)$ & $36(12.3 \%)$ & $11(3.8 \%)$ & $4(1.4 \%)$ \\
\hline & $\begin{array}{l}\text { Do things that need doing without being asked or } \\
\text { told }\end{array}$ & $133(45.5 \%)$ & $120(41.1 \%)$ & $16(5.5 \%)$ & $20(6.8 \%)$ & $3(1 \%)$ \\
\hline & I am punctual about coming to work & $89(30.5 \%)$ & $126(43.2 \%)$ & $48(16.4 \%)$ & $22(7.5 \%)$ & $7(2.4 \%)$ \\
\hline \multirow{2}{*}{$\begin{array}{l}\text { General } \\
\text { commitment }\end{array}$} & I am proud to be working for this health center & $49(16.8 \%)$ & $80(27.4 \%)$ & $64(21.9 \%$ & $51(17.5 \%)$ & $48(16.4 \%)$ \\
\hline & $\begin{array}{l}\text { I am glad that I work for this center rather than } \\
\text { other facilities in the country }\end{array}$ & $39(13.4 \%)$ & $32(11 \%)$ & $72(24.7 \%$ & $81(27.2 \%)$ & $68(23.3 \%)$ \\
\hline
\end{tabular}

PCA revealed the presence of 3 components with eigenvalues exceeding 1, explaining $64.193 \%$ of total variance. Each component contribute respectively $41.848 \%, 13.084 \%$ and $9.625 \%$. The internal reliability estimates in this sample (Cronbachs' alpha) of 0.601 .

Table 5. Reliability of instruments for measuring level of job motivation constructs, Gedeo zone public health centers.

\begin{tabular}{|c|c|c|c|}
\hline \multicolumn{4}{|l|}{ Rotated Component Matrix ${ }^{a}$} \\
\hline & \multicolumn{3}{|l|}{ Component } \\
\hline & General motivation & Carefulness & Organizational commitment \\
\hline Only I do this job to get paid & .879 & & \\
\hline I am often absent form work & .864 & & \\
\hline I feel emotionally drained at the end of every day & .823 & & \\
\hline Sometimes when I get up in the morning, I fear having to face another day a & .819 & & \\
\hline It is not a problem if I sometimes come late for work & .785 & & \\
\hline I am not satisfied with my colleagues in my work & .763 & & \\
\hline I do this job as it provides long-term security for me & .733 & & \\
\hline I feel very little commitment to this health center & .707 & & \\
\hline I do not think that my work in this health facility is valuable these days & .693 & & \\
\hline I always complete my tasks efficiently and correctly & & .775 & \\
\hline Do things that need doing without being asked or told & & .769 & \\
\hline I am punctual about coming to work & & .735 & \\
\hline I am proud to be working for this health center & & & .848 \\
\hline I am glad that I work for this center rather than other facilities in the country & & & .835 \\
\hline
\end{tabular}

After data reduction in to 14 items to determine level of job motivation the following formula (Equation 2) used [52]. Percentage scale score is calculated for each participants of the study.

$$
\text { Percentage Scale Score }=\left(\frac{\text { Actual mean score-Potential Minimum }}{\text { Potential Maximum-Potential Minimum }}\right) * 100 \%
$$

The 14 items each has 5 point Likert scale, potential Minimum score will be 14 since the minimum score for 
Likert scale is one, potential maximum will be 70 (fourteen time the highest score five; $14 \times 5=70$ ). The actual mean score is calculated for each 292 health care professionals participated in the study it falls in range between 20.43 and 80.36 , then after by substituting the values of actual mean score, potential minimum and maximum percentage scale score for level of motivation is calculated afterward, the resulting percentage mean score is quantized to show the level of job motivation, accordingly $61(20.9 \%)$ health care professionals has low motivation, 174 (59.6\%) medium motivation and $57(19.5 \%)$ were highly motivated. The box plot for level of motivation is presented just under here, the numbers around the $25^{\text {th }}$ quintile shows minimum values contributed by the corresponding respondents.

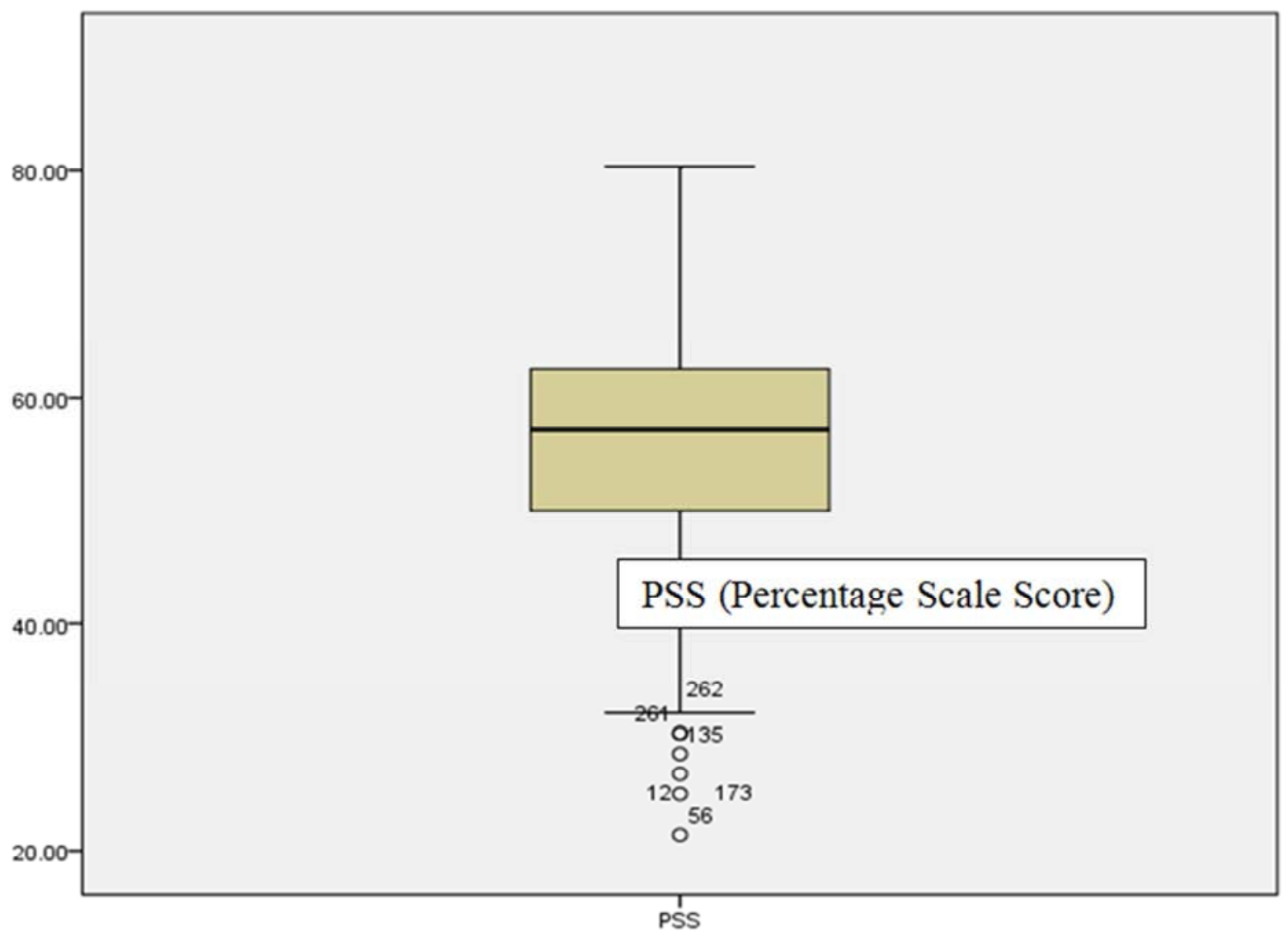

Figure 3. Box plot showing level of job motivation among health care professionals working in public health facilities of Gedeo zone, Southern Ethiopia, 2015 .

Association of different Factors that affect job motivation of health care professionals working in public health facilities of Gedeo zone, southern Ethiopia.

The bivariate analysis revealed that socio-demographic characteristics such as sex, age and work experience were significantly associated with level of job motivation among health care professionals working in public health facilities (Table $6)$.

Table 6. Showing simple linear regression of socio demographic characterics asscaition with job motivation among health care professionals working in public health facilities of Gedeo zone, southern Ethiopia.

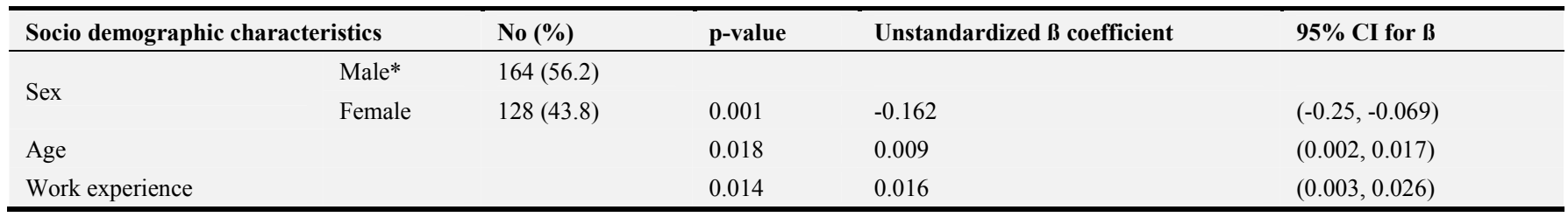

Sign $(*)$ used to indicate reference group with high frequency

From factor influencing job motivation in bivariate linear regression, feedback/supervision, effort, workload, opportunity for advanced level of jobs, resource availability, training, chance for education or career development, communication, work environment, lack of recognition/appreciation for work done, head of health center, miss use of HRM guideline, poor condition of service, inadequate salary and absence of promotion 
prospective were candidate for multiple linear regression analysis (Table 7).

Table 7. Showing simple linear logistic regression of factor influencing job motivation of health professionals working in public health facilities of Gedeo zone, southern Ethiopia.

\begin{tabular}{|c|c|c|c|c|c|}
\hline Variables & & No (\%) & P-value & Unstandardized ß coefficient & $95 \%$ CI for $B$ \\
\hline \multirow{2}{*}{ Feedback/ supervision } & Yes & $140(47.9)$ & 0.056 & 0.098 & $-0.003,-0.20)$ \\
\hline & $\mathrm{No}^{*}$ & $152(52.1)$ & & & \\
\hline \multirow{4}{*}{ Effort } & Strongly agree* & $38(13)$ & 0.800 & -.015 & $(-.094,0.952)$ \\
\hline & Agree & $99(34)$ & & & \\
\hline & Not sure & $82(28)$ & 0.387 & -.067 & $(-.220, .085)$ \\
\hline & Disagree & $73(25)$ & 0.096 & -0.127 & $(-0.227,0.023$ \\
\hline \multirow{2}{*}{ Workload } & Yes & $76(26)$ & 0.001 & -0.175 & $(-0.281,-0.07)$ \\
\hline & No* & $216(74)$ & & & \\
\hline \multirow{2}{*}{ Resource availability } & Yes & $140(47.9)$ & & & \\
\hline & No* & $152(52.1)$ & 0.000 & -0.197 & $(-0.288,-.105)$ \\
\hline \multirow{3}{*}{ Opportunity for advancement } & Yes & $46(15.8)$ & 0.019 & -0.154 & $(-0.28,-0.025)$ \\
\hline & No* & $238(81.5)$ & & & \\
\hline & I don't know & $8(2.7)$ & & & \\
\hline \multirow{2}{*}{ Training } & Yes & $118(40.4)$ & 0.001 & -0.312 & $(-0.4,-0.225)$ \\
\hline & No* & $174(59.6)$ & & & \\
\hline \multirow{2}{*}{ Education opportunity } & Yes & $56(19.2)$ & 0.031 & -0.131 & $-0.25,-0.012$ \\
\hline & No* & $236(80.8)$ & & & \\
\hline \multirow{2}{*}{ Working environment } & Yes & $146(50)$ & & & \\
\hline & No* & $146(50)$ & 0.001 & -0.251 & $(-0.34,-0.161)$ \\
\hline \multirow{4}{*}{ Communication } & Very satisfied & $38(13)$ & & & \\
\hline & Satisfied* & $99(34)$ & 0.516 & 0.036 & $0.073,0.145$ \\
\hline & Not satisfied & $82(28)$ & 0.518 & -0.31 & $-.125,0.063$ \\
\hline & Need improvement & $73(11)$ & 0.096 & -.127 & $-.277,0.023$ \\
\hline \multirow{2}{*}{ Lack of recognition } & Yes* & $226(77.4)$ & & & \\
\hline & No & $66(22.6)$ & 0.001 & -0.215 & $(-0.325,-0.106)$ \\
\hline \multirow{2}{*}{ Head of health center } & Yes & $91(31.2)$ & 0.097 & -0.079 & $-0.173,0.014)$ \\
\hline & No* & $135(46.2)$ & & & \\
\hline \multirow{2}{*}{ Miss use of HRM Guideline } & Yes & $74(25.3)$ & 0.037 & 0.114 & $0.007,0.222$ \\
\hline & No* & $152(52.1)$ & & & \\
\hline \multirow{2}{*}{ Poor condition of services } & Yes & $187^{*}$ & & & \\
\hline & No & 105 & 0.192 & -0.065 & $-0.163,0.033$ \\
\hline \multirow{2}{*}{ Inadequate salary } & Yes* & $210(71.9)$ & & & \\
\hline & No & $16(5.5)$ & 0.118 & -0.164 & $-0.37,0.042$ \\
\hline \multirow{2}{*}{ No Promotion prospective } & Yes* & $119(40.8)$ & 0.004 & 0.140 & $0.045,0.234$ \\
\hline & No & $107(36.6)$ & & & \\
\hline
\end{tabular}

The final regression model shows that except work experience the rest variables were negative predictors of job motivation. All of the variables were strong predictors of job motivation with ( $\mathrm{p}<0.01$ but lack of recognition/appreciation predict the job motivation with $(\mathrm{p}<$ 0.05) (Table 8).

Female health care providers had an average of 0.213 unit lower job motivation score when compared with their counterpart (95\% CI -0.256 to -0.094) (Table 8).

As work experience increase by one year the job motivation scale increase by 0.134 unit with $95 \%$ CI $(0.004$ to 0.024 ) (Table 8).

Health care providers who complain the working environment is not good their motivation is lower by 0.211 unit than those who works in good environment (Table 8).

Those health care professionals who are not satisfied by communication between management and staff their motivation score decline by 0.127 than those satisfied by the communication (Table 8).

If health care providers were not recognized/appreciated by their immediate supervisor or manger their motivation score decrease by 0.111 unit than those got recognition from manager or clients (Table 8 ).

A 34 years old male Health Care Professional from one HC said:

"Most of the time appreciation comes from patients which is most important, because it is sincere and heartfelt, it is more than money, we can't compare it with money".

If Health care providers were not supervised or given feedback on their job their job motivation score fall by 0.116 unit than those who get feedback from their Boss (Table 8).

A 31 years old Female Health Care Professional from one HC said:

"... First of all the supervision/feedback is low in frequency and irregular, at the time of supervision they remind you of the rules and control you, while individual 
efforts go unnoticed, mistakes or shortcomings are noticed immediately..."

Those health care providers who complain that their salary is inadequate their job motivation score is lower by 0.136 unit than those health care professionals considering their salary is enough with $95 \%$ CI (-0.422 to -0.066) (Table 8).

A 35 years old Male Health Care Professional from one HC said:

"... We are living in a hard condition: salary itself can never sustain even food for the whole month, not to talk about other issues, even the part time pay is not in line with pay in other regions of the country, we are paid 41per a duty..."

Those health care professionals not getting equal chance for training than their counterpart their job motivation score is lower by 0.35 unit.
A 32 years old male Health Care Professional from one HC said:

"... It is necessary to make everybody participate in training opportunities, not always to privilege the same..."

Those health care professionals who are working in area with less medical supplies (resource availability) their job motivation scale score were lower by 0.170 unit than those who works with enough materials $(95 \% \mathrm{CI}-0.221$ to -0.056$)$ (Table 8).

A 45 years old male Human resource management coordinator from one $\mathrm{HC}$ said:

"... Now a day governmental health care institutions are becoming weak, they are not providing expected services for the community, most of the time drugs were not available, even for simple lab investigation they sent clients to private clinics..."

Table 8. Showing determinants of job motivation among health care professionals working in public health facilities of Gedeo zone, southern Ethiopia.

\begin{tabular}{|c|c|c|c|c|c|}
\hline Variables & & No (\%) & Unstandardized $B$ coefficient & Standardized $B$ coefficient & $95 \%$ CI for $B$ \\
\hline (Constant) & & & 0.398 & & $(0.283,0.512)$ \\
\hline \multirow{2}{*}{ Sex } & Male* & $164(56.2)$ & & & \\
\hline & Female & $128(43.8)$ & -.175 & $-0.213 * * *$ & $(-.256,-0.094)$ \\
\hline Work experience & & & .041 & $0.134 * * *$ & $(0.004,0.024)$ \\
\hline \multirow{2}{*}{ Working Environment } & Yes* & $146(50)$ & & & \\
\hline & No & $146(50)$ & -.172 & $-.211 * * *$ & $(-.254,-.091)$ \\
\hline \multirow{4}{*}{ Communication } & Very satisfied & $147(50.3)$ & & & \\
\hline & Satisfied* & $80(27.4)$ & & & \\
\hline & Not satisfied & $33(11.3)$ & & & \\
\hline & Need improvement & $32(11)$ & -.166 & $-.127 * * *$ & $-.293, .039$ \\
\hline \multirow{2}{*}{ Lack of recognition } & Yes* & $180(61.6)$ & & & \\
\hline & No & $112(38.4)$ & -.108 & $-.111 * *$ & $(-.218,0.001)$ \\
\hline \multirow{2}{*}{$\begin{array}{l}\text { Feedback/ } \\
\text { supervision }\end{array}$} & Yes & $91(31.2)$ & -.102 & $-.116^{* * *}$ & $(-.199,-.005)$ \\
\hline & No* & $135(46.2)$ & & & \\
\hline \multirow{2}{*}{ Inadequate salary } & Yes* & $210(71.9)$ & & & \\
\hline & No & $16(5.5)$ & -.243 & $-.136^{* * *}$ & $(-.420,-.066)$ \\
\hline \multirow{2}{*}{ Training } & Yes* & $160(54.8)$ & & & \\
\hline & No & $132(45.2)$ & -.269 & $-.329 * * *$ & $(-.353,-.185)$ \\
\hline \multirow{2}{*}{ Resource availability } & Yes & $140(47.9)$ & -.138 & $-.170 * * *$ & $(-.221,-.056)$ \\
\hline & No* & $152(52.1)$ & & & \\
\hline
\end{tabular}

$\left(^{*}\right)$ reference category, $(* *)$ Significant at $0.05,(* * *)$ significant at $<0.001$

$N B$ :-Negative values of both unstandardized and standardized $\beta$ show that the corresponding factors are the negative predictors for Job Motivation, whereas the positive values indicate that the factors are positive predictors.

Among Health care professionals working in public health center of Gedeo zone 37 (22.6\%) male and 24 (18.8\%) female had low job motivation, $98(59.8 \%)$ male and 76 (59.4\%) female had medium job motivation and 29 (17.7\%) male and 28 (21.9\%) females had higher job motivation.

\section{Discusion}

Job motivation plays an important role in contributing to positive consequences to the quality of the institutions especially in health care organizations. Therefore, the results presented here are crucial, in sum, the main objective to be attained is to determine level of job motivation and associated factors in public health centers. Results from this research indicated that sex, work experience, working environment, feedback/supervision, Resource availability, communication, inadequate salary, training distribution and lack of recognition for the work done in public health centers were the main determinant of job motivation.

It is evident from the study that $26 \%$ (76) of health care professionals are complain work overload this agrees with findings from South Africa and Northern Viet Nam [38, 4243]. The similarity is might be due to health care services are labour intensive by its nature and also might be lack of resource to employee adequate health care professionals.

In this study around $84.6 \%$ of health care professionals have no clear ideas regarding continuing education, this figure is nearer similar with study done in developing countries (Africa and Asia) which is $80 \%$, to provide health care services $47.9 \%$ of health care professionals face 
shortage of basic resource supplies (medical equipment and supplies) which is clearly shown in study done in developing counties [44]. This is might be due to lack of awareness on educational curriculum of the country and for shortage of medical equipment and supplies the similarity is might be due to poor management system of stock or lack of budget (resource) to purchase.

A 31 years old Female Health Care Professional from one HC said:

"... why I am here is to serve the community by providing expected health services from me... even though this health center is serving for more than 30,000 population it lacks even basic equipment for example BP-apparatus, which is cheap to buy..."

The result indicate that $95 \%$ of professionals feel that the salary is not compensator, opportunity for advancement is only $15.8 \%, 90.7 \%$ of health care professionals not recognized for their performance and only $6.2 \%$ of them are rewarded this finding is in line with study done in Rwanda, motivation of health care workers are closely related to the presence of opportunities for promotion, salary increases, working conditions and supervision [45]. This is might be due to financial inflation all over the world, rewarding mechanisms is not cultured in in health sectors of those countries.

Communication relationship among management and staff lower job motivation score by 0.127 units, similarly lack of recognition and poor working environment respectively lower 0.111 and 0.211 units of job motivation score this finding is similar with study done on the motivation of health sector workers in Mali, on 370 health workers identified motivating factors such as salary/compensation, receiving training, appreciation and receiving recognition, receiving promotion, receiving incentives, working within a team spirit [41].

This study revealed that there is association of sex with level of job motivation, study done in Addis Abeba, does not show significance difference in work motivation based on gender again study done in Zambia shows females were more motivated than males but this study shows that there is difference among male and female [43,50]. There is no apparent explanation why not female health care professionals were less motivated with their job. Possibly Maybe perception of affirmative action since most of them work in rural health centers and also might male consider the phenomena are fair; considering resource constraint and week management system of health sector, the issue of gender needs further investigation.

A 34 years old male Health Care Professional from one HC said:

"... confidently I can say, the salary is very low especially paid for diploma graduate, the government is not providing us transport service daily we are paying 14 ETB for taxi, there is unfair promotions and transfer procedures, it is fevered for those who has money and social ties, there is "drought of equipment's and supplies", almost all staff rent houses since the health center is far from Woreda towns which is also covered by our salary... all this thing affect my motivation" this is similar with a study done in Ghana on health worker motivation in the public sector revealed low salary, lack of essential equipment, supplies, delayed/unfair promotions, personal means of transport, inadequate inservicing training, official transport for work, inconvenient or unfair transfer procedures as been factors affecting motivation of health workers [47]. This is might be due to poor management of health system and lack of resource to fulfill the existing gaps.

This study revealed factors such as opportunity for training, relation among with colleagues, working environment, basic medical equipment and supplies as motivating factors this is also true with study done in Indian two state [35]. This is due to Herzberg theory of motivation; the theory consider the mentioned factors as hygienic (extrinsic) factors which affects motivation so this both study is in line with the theories of two factors of Herzberg.

If Feedback is not given by manager or supervisor for health care professionals their job motivation score decline by 0.116 unit motivated, unavailability of tools and materials to work with lower by 0.170 units of job motivation score which is similar with study done in north-eastern Nigeria [38]. This is might be due to the health centers managers or supervisors were not using feedbacks and supervision as tools for performance evaluation, quality management and initiate tools for motivation.

A 31 years old male Health Care Professional from one HC said:

"first of all the supervision is low in frequency and irregular, at the time of supervision they remind you of the rules and control you, while individual efforts go unnoticed, mistakes or shortcomings are noticed immediately"

Judging from the answers provided, the feedback that health workers receive from their supervisors in public health facilities usually centres on specific shortcomings or technical aspects of service provision.

The study identified opportunity to continue education and professional's development as important influential factors of job motivation which is similarly identified by WHO [4]. This is might be due to absence of curriculum for further education or lack of awareness by lower level health care professionals.

Slightly above three quarter $77 \%$ of health care professionals believes that they got proper assistance from the regional health beuro and Ministry of Health which is contradicted with finding from Mali where there is lack of proper assistance from Ministry but lack of supervision, continuing education, absence of housing and the absence of basic amenities such as water and electricity were considered to negatively affect work motivation in both case [46], which is strongly supported by

A 30 years old male Health Care Professional from one HC said:

“... At country level we have best policy and strategy but what is wrong is its administration in lower level which is totally irrespective of the written document,, this health 
center is very far from Woreda town where there is no water, network and electricity, even we don't get food sometimes, Regionals Health Beuro ordered to build house but the zonal and Woreda health office is not doing in such a way this is might be due to lack of resources.

This study shows that $93 \%$ of health care professionals said the salary is not compensatory of their services and $53 \%$ of services are provided in poor conditions this is similar with study done in Northern Viet Nam [36]. This is might be due to shortage of resource to allocate in sufficient amount to meet unmet need of health care professionals and financial inflation.

\section{Conclusion}

All most all of health care professionals were not satisfied by current salary. The professionals also complain that duty payment is not along with national pay; around half of health care professionals work in health centers that lacks basic medical equipment's, drug and laboratory supplies, above half of health care professionals not get equal chance for training most of the time the health center heads gives for irrelevant (unconcerned) individual as evident from in-depth interview, only less than one fifth of health professionals clearly now that they have chance of continuing further education or career development.

\section{References}

[1] Kanfer R. Measuring job Motivation from three district in Zambia, Working Paper 1. Bethesda MD: Partnerships for Health Reform, BMC, Abt Associates Inc 1999. vol 2 (4): 12-14.

[2] Helepota, H. A. Motivation Theories and their Application in Construction Cost in Kenya. Kenyan national health $\mathrm{J}$ asso. 2005; vol (5): 23-27.

[3] Teshager K, Ma A, Assfaw S, Mba Y, Neda Y, Mba L, et al. An Exploration of Competency Gaps in Human Resource Management in the Health Sector in Ethiopia Ethiopian J health development 2006; vol 1 (5): 32-35.

[4] World Health Organization. The World Health Report. Working Together For Health, 2006; vol 27 (14): 16-19.

[5] Songstad NG. Health worker motivation in a low-income context. Kampala. BMC Health Services Research 2012; vol 6 (9): 77-79.

[6] Willis-Shattuck, M., Bidwell, P., Thomas, S., Wyness, L., Blaauw, D., and Ditlopo, P. Motivation and retention of health workers in developing countries: A systematic review. BMC Health Services Research 2008, 8, 247.

[7] Kamanzi J, Degree H. motivation levels among nurses working in public health facilities of Rwanda. BMC Health Services Research 2011; 13 (2): 119-31.

[8] Garcia-Prado, A. "Sweetening the Carrot: Motivating Public Physicians for Better Performance'”. The World Bank, Policy Research Working Paper 3772. Ghana Health Service annual report of performance 2007.
[9] Rowe, A. K., de Savigny, D., Lanata, C. F, and Victora, C. G. "How Can We Achieve and Maintain high quality performance of healthcare workers in low resource setting. The lancet 366, 2008; 1026-1035.

[10] Dieleman, M., Toonen, J., Toure, and Martineau T. 'The Match between Motivation and Performance Management of Health Sector Workers in Mali 2006. (http:/www.humanresourcs-health.com/content/4 (Accessed 2/12/2014).

[11] Franco, L. M., Bennett, S., and Kanfer, R. Health Sector Reform and Public Sector Health Worker Motivation: A conceptual Framework. Social Science and Medicine, 2011, 54 (8), 1255-1266.

[12] Dieleman, M., Cuong, P., Anh, L., and Martineau, T. "Identifying Factors for Job Motivation of Rural Health Workers in North Viet Nam''2012. (http:/www.humanresourcs-health.com/content//1/10). (Accessed on 22/11/2014).

[13] Chen, L, Evans, T., Anand, S., Boufford, J. I., et. al. Human resources for health: overcoming the crisis. Lancet 2008; 364; 1984-1990.

[14] WHO, Taking Stock: Health worker shortages and the response to AIDS. HIV? AIDS Programme, World Health Organization, 2007. Engineering, Vol. 47, No. 3 pp. 14-35.

[15] Kebede S, Mantopoulos J, Ramanadhan S, Cherlin E, Gebeyehu M, et al. Educating leaders in hospital management: a pre-post study in Ethiopian hospitals. Global Public Health $2012 ; 7$.

[16] Delobelle P, Rawlinson JL, Ntuli S, Malatsi I, Decock R, et al. Job satisfaction and turnover intent of primary healthcare nurses in rural South Africa: a questionnaire survey 2011.

[17] Serneels P, Barr A, Serneels P. Intrinsic Motivations and the Non-Profit Health Sector: Evidence from Ethiopia. 2010;(4746).

[18] Melkidezek T. Leshabari, Eustace P. Y. Muhondwa 1, M. A. Mwangu, Naboth A. A. Mbembati "Motivation of Healthcare Workers in Tanzania: A Case Study of Muhimbili National Hospital', East African Journal of Public Health, 2008 Volume 5 Number 1.

[19] Mbindyo, P. Lucy Gilson, Duane Blaau and Mike English "Contextual influences on Health worker motivation in district hospitals in Kenya', Implementation Science 2009, 4: 43 doi: 10.1186/1748-5908-4-43.

[20] Girma S, Yohannes AG, Kitaw Y, Ye-ebiyo Y, Seyoum A, Desta H. Human Resource Development for Health in Ethiopia: Challenges of Achieving the Millennium development Goals 2009.

[21] World Bank. "Education in Ethiopia: Strengthening the Foundation for Sustainable Progress, Human Development Department (AFTH3). 2005 February.

[22] Fauziah w, yusoff w, kian ts, talha m, idris m. herzberg' s two factors theory on work motivation: does its work for todays environment? mbc 2013; 2 (5): 18-22.

[23] Alliance GHW. GUIDELINES : incdntive for health care professionals. BMC 2008; vol 5 (4): 10.

[24] Mullins, J. Management and Organizational Behavior. New Jersey: FT Prentice Hall, Eastern Mediterranean Health Journal, 2009, Vol. 13, No. 5. 
[25] Kressler, H. Motivate and Reward: Performance Appraisal and Incentive System for Business Success. New York: Palgrave Macmillan, PubMed 2008; vol 5 (3): 37-38.

[26] Jones, G, and George, J, Contemporary Management, Boston: McGraw-Hill 2006; 10.

[27] Petcharak, P., The Assessment of Motivation in the Saint Paul Hotel Employees, retrieved from: http://www2.uwstout.edu/content/lib/thesis/2002/2002petchar akp.pdf, 2007 (Accessed on: 12/12/2014).

[28] Alderfer, Clayton P., an Empirical Test of a New Theory of Human Needs; Organizational Behavior and Human Performance, retrieved from: http://dx.doi.org/10.1016/00305073(69)90004?X, 1969 (Accessed on: 23/12/2014).

[29] Lai, C. (2009), Motivating Employees through Incentive programmes retrieved from: https://publications.theseus.fi/bitstream/handle/10024/17561/j amk_123744488_5.pdf? sequence $=2$, (Accessed on: $11 / 1 \overline{2} / 2014)$.

[30] Herzberg, Frederick, the Motivation to Work, New York: John Wiley and Sons 1959; 8 .

[31] Griffin. R,, Management, Boston: Houghton Mifflin Company East African Journal of Public Health 2008; vol 4 number 3: 56-57.

[32] Habib, M. N., Mukhtar, S., Jamal, W. Factors Influencing the Teachers Intentions to Quite in Private Sector Higher Educational Institutions of Pakistan. Interdisciplinary Journal of Contemporary Research Business, 2010 vol.?1, p.?12.7.

[33] Wong, S., Siu, V., and Tsang, N.,. The impact of demographic factors on Hong Kong hotel employees' choice of job? Related motivators. International Journal of Contemporary Hospitality Management, vol.? 11 (5), pp. 230? 241. Retrieved from: http://www.cabdirect.org/abstracts/20001804674.html;jsession $\mathrm{id}=56 \mathrm{~B} 0080542 \mathrm{E} 23 \mathrm{~B} 43 \mathrm{C} 3 \mathrm{FDBFC} 62637 \mathrm{D} 55 \mathrm{~A},(2009$ (accessed on: 02/12/2014)

[34] McShane. S, L., and Von Glinow. M, A., Organizational Behavior, New York, McGraw-Hill East African Journal of Public Health 2010; vol 12 number 16: 16-18

[35] Peters D. H, Subrata Chakraborty, Prasanta M., Laura S. “Job satisfaction and motivation of health workers in public and private sectors: cross-sectional analysis from two Indian states"' 2010. (http:/www.human-resourcshealth.com/content/8/1/27). (Accessed on 17/12/2014).

[36] Dieleman, M., Cuong, P., Anh, L., and Martineau, T. (2009) "Identifying Factors for Job Motivation of Rural Health Workers in North Viet Nam"' 2009, (http:/www.humanresourcs-health.com/content//1/10). (accessed on 20/12/2014).

[37] Dieleman, M., Cuong, P., Anh, L., and Martineau, T. "Identifying Factors for Job Motivation of Rural Health Workers in North Viet Nam''2012. (http:/www.humanresourcs-health.com/content//1/10). (Accessed on 22/11/2014).

[38] Oluwabunmi, O. C., Joseph, T. A., Clara L. E, Amos, P. B, and Ayuba, I. Z. (). "Perceptions of working conditions amongst health workers in state-owned facilities in northeastern Nigeria"' 2010, (www.annalsafrmed.org), (accessed on 12/12/2014).

[39] Kebriaei A. I and M. S. Moteghedi I. "Job satisfaction among community health workers in Zahedan District, Islamic
Republic of Iran', Eastern Mediterranean Health Journal, 2009, Vol. 15, No. 5.

[40] Garcia-Prado, A. "Sweetening the Carrot: Motivating Public Physicians for Better Performance'”. The World Bank, Policy Research Working Paper 3772. Ghana Health Service annual report of performance 2007.

[41] Dieleman, M., Toonen, J., Toure, and Martineau T. 'The Match between Motivation and Performance Management of Health Sector Workers in Mali 2006. (http:/www.humanresourcs-health.com/content/4 (Accessed 2/12/2014).

[42] Pillay, R. (2009) "Work satisfaction of professional nurses in South Africa: a comparative analysis of the public and private sectors", (http:/www.human-resourcshealth.com/10.1186/1478-4491-7-15). (accessed on $15 / 11 / 2014)$.

[43] Wilbroad Mutale, Helen Ayles, Virginia Bond, Margaret Tembo Mwanamwenge and Dina Balabanove "Measuring health workers motivation in rural health facilities": base line results from three district of Zambia. Mutale et al. Human Resource for Health 2013, 11: 8, http:/WWW.humanresourec-health.com/content/11/1/8 (accessed on 15/11/2014).

[44] Franco LM, Bennett S, Kanfer R. Health sector reform and public sector health worker motivation a conceptual framework. Social Science and Medicine. 2008 PubMed; 54: 1255-1266. Doi: 10.1016/S0277-9536 (01) 00094-6.

[45] J. Kamanzi, Z. Z Nkosi, Motivation levels among nurses working in public health facilities of Rwanda PubMed 2008; vol 7 (2): 13-15.

[46] Ogenna Manafa, Eilish McAuliffe, Fresier Maseko, Cameron Bowie, Malcolm MacLachlan and Charles Normand, Retention of health workers in Malawi: perspectives of health workers and district management, Human Resources for Health 2009, 7: 65 doi: 10.1186/1478 4491-7-65.

[47] Agyepong, I. A., Patricia Anafi, Ebenezer Asiamah, Evelyn K. Ansah, Daniel A. Ashon and Christiana Narh-Dometey "Health worker (internal customer) satisfaction and motivation in the public sector in Ghana". International Journal of Health Planning and Management 2008. (www.interscience.wiley.com). (accessed on 12/12/2014).

[48] Lin P Y (2007), The Correlation between Management and Employee Motivation in SASOL Polypropylene in Business, South Africa, retrieved from: http://upetd.up.ac.za/thesis/available/etd?08042008?92827, (Accessed on 10/12/2014).

[49] Latham, G. Work Motivation: History, Theory, Research, and Practice. California: Sage Publications, 2007; vol 4 number 7: 19-20.

[50] Nebiat Nigussie. Relationship between rewards and nurses' work motivation in Addis Ababa hospitals Ethiop J Health Sci. Jul 2012; 22 (2): 107-112. PMCID: PMC3407833.

[51] Marjolein Dieleman, et al I believe that the staff have reduced their closeness to patients': an exploratory study on the impact of HIV/AIDS on staff in four rural hospitals in Uganda, PubMed 2007, http://www.biomedcentral.com/14726963/7/205/prepub_(Accessed on 10/12/2014).

[52] Joses Muthuri Kirigia and Gatwiri Kirigia. The essence of Governance in health development open access, international archive of medicine. Kirigia and Kirigia international archives of medicine 2011. 